\title{
Comparison of the existing photovoltaic power plant performance simulation in terms of different sources of meteorological data
}

\author{
Krystian Cieslak $^{1, *}$, Piotr Dragan ${ }^{1}$ \\ ${ }^{1}$ Lublin University of Technology, Institute of Renewable Energy Engineering, Faculty of \\ Environmental Engeneering, ul. Nadbystrzycka 40B 20-618 Lublin, Poland.
}

\begin{abstract}
Detailed and reliable design of a photovoltaic (PV) power plant cannot be underestimated. In terms of energy production forecasts and legal issues concerning financing - simulation performance of the PV installation is a very important problem for both the investor and the bank. In order to simulate the performance of the PV system one has to choose proper meteorological database which would be the most reliable on the installation site. Since different meteorological databases have different measurements methods and analysis, choosing the best one is not a trivial problem. In order to find the best meteorological data source for PV simulation performance under eastern Poland conditions, PVSYST software has been used. Detailed project of an 1.39 MWp PV power plant located in Bordzilowka in the east of Poland was introduced into the software. Choosing different meteorological data bases, monthly and yearly energy production was established. The simulation results were compared with the real data obtained from the PV power plant.
\end{abstract}

\section{Introduction}

The modern World is dependent on electrical energy in every aspect of its existence. Starting from small everyday usage like smart phones and computers, through more and more popular electric cars, ending on big industrial applications, electrical energy becomes the most reliable and versatile form of energy. World demand for energy increases every year and since conventional sources of energy like fossil fuels at some point would be exploited, developing and investing in renewable energy sources seems to be the best idea. That kind of approach will ensure that world energy demand will be fulfilled despite of fossil fuel shortage. The biggest renewable energy source on our Planet is the Sun, so energy management coming from our Star should be taken into account while thinking about sustainable development of humanity. One way to harness solar energy is to use photovoltaic systems which convert solar energy directly into the electricity. During the past few years that kind of energy production is getting more popular and the number of megawatts installed every year all over the world increases rapidly [1] (Fig. 1).

\footnotetext{
${ }^{*}$ Corresponding author: k.cieslak@pollub.pl
} 
Before installing a photovoltaic (PV) system, an investor has to establish the approximate annual and monthly energy production of the PV farm. This information is required to create a reliable project which should be optimized for needs and expectations of the investor as well as for specific legislation and support programs available at the place of investment. Banks also call for this information during the procedure for obtaining a loan. That is why getting the most dependable data about energy production cannot be overestimated. There are many software programs on the market that can provide such information, but every one of them calculates the energy yield of a PV system depending on specific meteorological data obtained from different meteorological bases. One of the free sources of the meteorological data is Photovoltaic Geographical Information System (PVGIS) [2] which provides satellite data from four meteorological sources: PVGISCMSAF, PVGIS-SARAH, PVGIS-ERA5, PVGIS-COSMO. The biggest uncertainty while establishing energy yield comes from solar radiation data, that is why the goal of this work is to establish the best meteorological data source coming from PVGIS for conditions in eastern Poland.

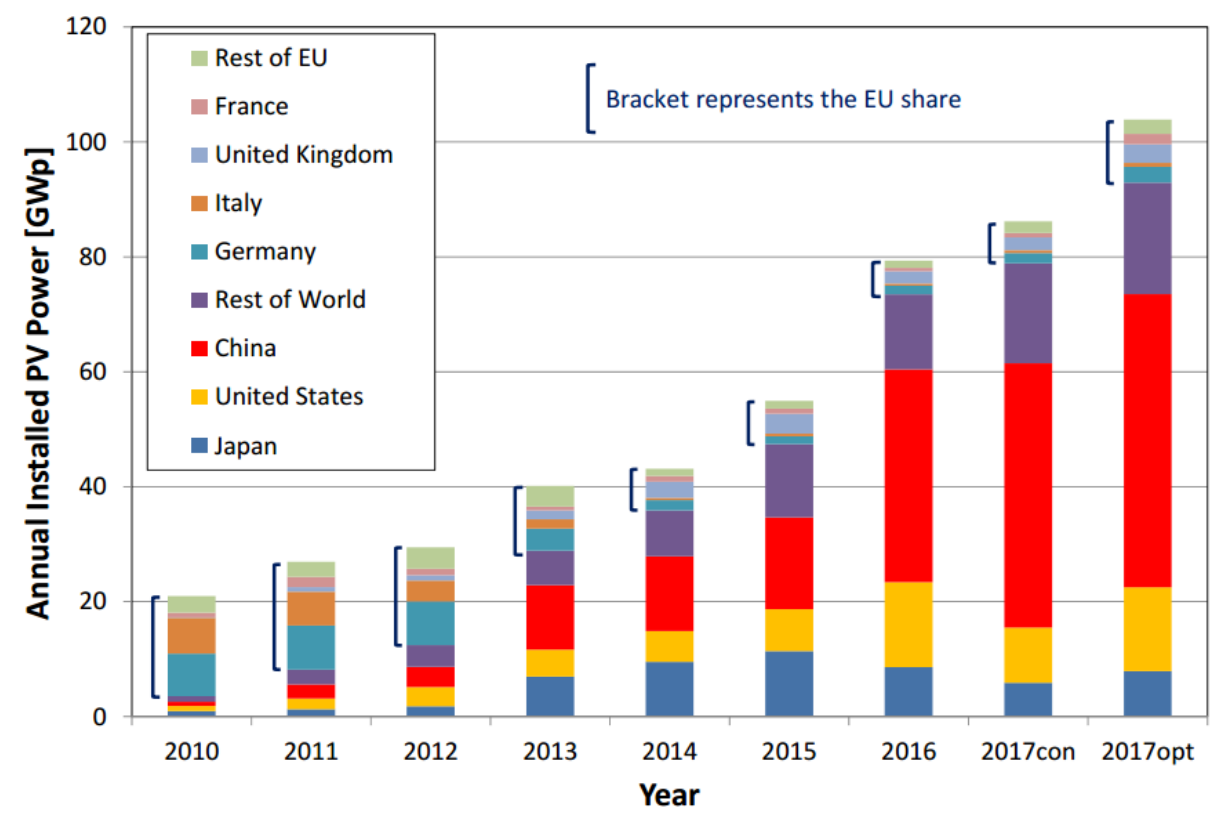

Fig. 1. Annual PV system installations from 2010 to 2017 [1].

\section{Experimental}

\subsection{Meteorological data}

In order to have reliable meteorological data coming from ground measurements, measuring stations have to fulfil very strict rules [2]:

- Only high quality measurement sensors should be used;

- Measurements should be performed at least every hour;

- Sensors should be calibrated regularly;

- Sensors should be cleaned regularly;

- Data should be available for a long time period, preferably 10 years or more. 
Relatively low number of ground based measurement devices that can fulfil these rules is the reason that the satellite measurements are used more often. Usually geostationary satellites make required observations. The advantages of using such data are [2]:

- solar radiation data are available in the whole of the area covered by the satellite images,

- normally long time series are available, up to 30 years or more.

The main disadvantage is a necessity to use sophisticated numerical methods to calculate solar radiation on the ground level. This kind of calculation requires also data concerning atmospheric water vapour, ozone and aerosols.

This work focuses on four satellite based, meteorological data available for free on the PVGIS web site.

\subsubsection{PVGIS-CMSAF}

The CMSAF (Satellite Application Facility on Climate Monitoring) solar surface irradiance retrieval is based on radiative transfer calculations using satellite-derived parameters as input. It is a part of the European Organisation for the Exploitation of Meteorological Satellites (EUMETSAT) ground segment and part of the EUMETSAT network of Satellite Application Facilities. It contributes to the operational long term monitoring of the climate system by providing Essential Climate Variables related to the energy and water cycle of the atmosphere like cloud parameters, surface and top of atmosphere (TOA) radiation budget components and atmospheric water vapour [3]. The CMSAF contributes to the sustainable observation of the climate system by providing Essential Climate Variables related to the energy and water cycle of the atmosphere. A central task of the CMSAF is the generation of satellite based Climate Data Records (CDRs). A climate data record is a time series of sufficient length, consistency, and quality to determine climate variability and change [4]. The data are available from 2007 to 2016.

\subsubsection{PVGIS SARAH}

The Surface Solar Radiation Data Set - Heliosat (SARAH) is a satellite-based climatology of the solar surface irradiance, the surface direct normalized irradiance and the effective cloud albedo derived from satellite observations of the visible channels of the MVIRI and SEVIRI instruments onboard the geostationary Meteosat satellites. The data are available from 2005 to 2016 and cover the region $\pm 65^{\circ}$ longitude and $\pm 65^{\circ}$ latitude. The products are available as monthly, daily, and hourly averages on a regular latitude/longitude grid with a spatial resolution of $0.05^{\circ} \times 0.05^{\circ}$ [4].

\subsubsection{PVGIS-ERA5}

This data is produced by the European Center for Medium-range Weather Forecast (ECMWF). ERA5 provides hourly estimates of a large number of atmospheric, land and oceanic climate variables. The data cover the Earth on a $30 \mathrm{~km}$ grid and resolve the atmosphere using 137 levels from the surface up to a height of $80 \mathrm{~km}$. ERA5 includes information about uncertainties for all variables at reduced spatial and temporal resolutions [5]. The data available data covers a time period from 2010 to 2016 .

\subsubsection{PVGIS -COSMO}

The COSMO-Model (COnsortium for Small-Scale Modelling) is a nonhydrostatic limitedarea atmospheric prediction model. It has been designed for both operational numerical weather prediction (NWP) and various scientific applications on the meso- $\beta$ and meso- $\gamma$ scale. The COSMO-Model is based on the primitive thermo-hydrodynamical equations describing compressible flow in a moist atmosphere [6]. This model uses grid spacing around $7 \mathrm{~km}$. The available data covers a period from 2005 to 2015 . 


\subsection{Photovoltaic Power Plant characteristic}

\subsubsection{Installation conditions}

The photovoltaic power plant discussed in this work is located in the eastern part of Poland (latitude $51^{\circ} 51 \mathrm{E}$, longitude $23^{\circ} 10 \mathrm{~N}$ ) in Bordzilowka. It was created as a result of cooperation of local governments from five boroughs with a local government company "Energia Dolina Zielawy" [7]. The region where the investment is localized is characterised by very good irradiation conditions compared to the rest of the country (Fig. 2). During the year 2015 - the year that will be analysed in this work, yearly Sunshine Duration exceeds $2,000 \mathrm{~h}$. Very good solar conditions were one of the motivations for the local governments to invest in solar energy.

According to the PN-EN 12831standard [8], the installation site is situated in the IV climate zone. It means that the average yearly temperature is $6.9^{\circ} \mathrm{C}$, and the lowest outside temperature taken into account in the project reaches $-22^{\circ} \mathrm{C}$.

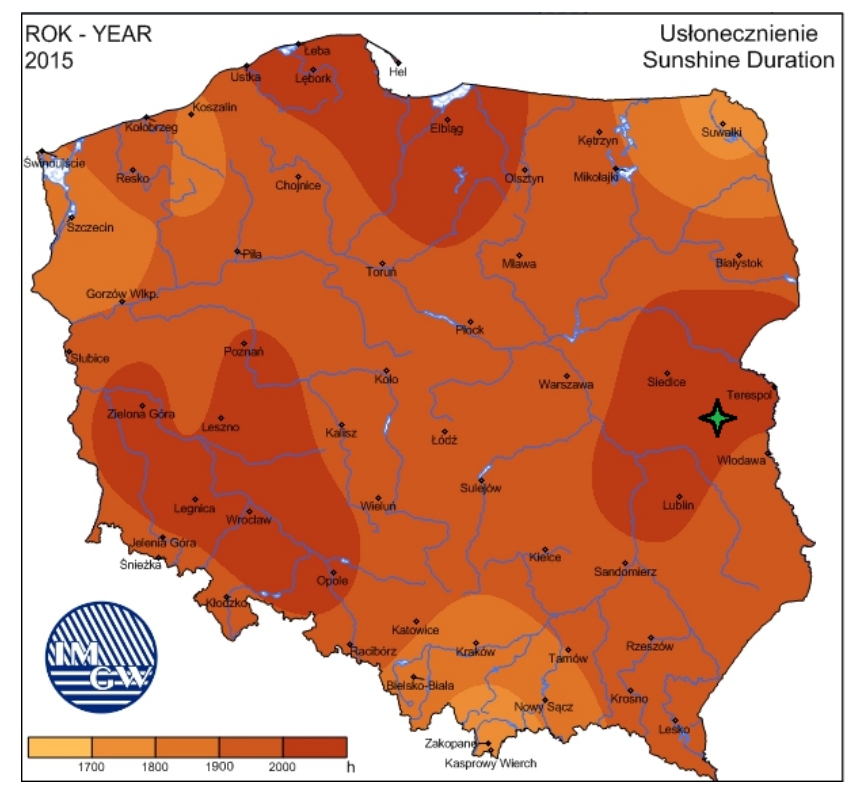

Fig. 2. Sunshine duration map of Poland during the year 2015 [9]. The green star points to the localisation site of the PV power plant in Bordzilowka.

\subsubsection{PV power plant configuration}

This PV power plant contains 5,560 silicon polycrystalline modules JC250M-24/Bb with power measuring $250 \mathrm{Wp}$ in Standard Testing Conditions (STC). It sums up to $1.39 \mathrm{MWp}$ power of the power plant. Modules are connected to 70 inverters - $20 \mathrm{~kW}$ each. Inverters were produced by Delta Energy - Solar inverter SOLIVIA 20 EU G4 TL. This model contains two symmetrical, independent Maximal Power Point Tracker (MPPT) inputs which are responsible for obtaining maximal power from the connected modules during changes of environmental conditions. Configuration of the connections to each inverter are presented in the Table 1. Additional parameter $\left(\mathrm{P}_{\text {nom }}\right.$ ratio) seen in the Table 1, gives information about overload on corresponding MPPT Input.

Modules were installed vertically in two rows on aluminium supporting structures. To reduce negative impact related to self-shading, strings were installed as follows: one string as a bottom row and a second, independent string as an upper row (dashed line seen on the in 
Fig. 3 separates the strings). The tilt angle is $36^{\circ}$ and azimuth angle $-4^{\circ}$. Distance between rows is $9 \mathrm{~m}$. The PV power plant is situated on a grass field that ensures good air circulation.

Table 1. Configuration of electrical connections to each inverter.

\begin{tabular}{|c|c|c|c|c|c|c|}
\hline $\begin{array}{l}\text { Total power of the modules } \\
\text { connected to the inverter }\end{array}$ & No. of inverters & Total No. of the modules & MPPT Input & \begin{tabular}{|l|}
$\begin{array}{l}\text { No. of modules } \\
\text { in one string }\end{array}$ \\
\end{tabular} & No. of strings & Pnom ratio \\
\hline \multirow{2}{*}{$21.25 \mathrm{~kW}$} & \multirow{2}{*}{46} & \multirow{2}{*}{85} & INPUTA & 17 & 3 & 1.27 \\
\hline & & & INPUT B & 17 & 2 & 0.85 \\
\hline \multirow{2}{*}{$17 \mathrm{~kW}$} & \multirow{2}{*}{22} & \multirow{2}{*}{68} & INPUT A & 17 & 2 & 0.85 \\
\hline & & & INPUT B & 17 & 2 & 0.85 \\
\hline \multirow{2}{*}{$19.25 \mathrm{~kW}$} & \multirow{2}{*}{2} & \multirow{2}{*}{77} & INPUT A & 15 & 3 & 1.13 \\
\hline & & & INPUT B & 16 & 2 & 0.8 \\
\hline
\end{tabular}

\subsection{PVSYST simulations}

In order to compare four meteorological data available on the PVGIS website PVSYST v6.70 [10] software was used. The PV system described in the 2.2.1 section (Tab. 1) was introduced to the software as five independent sub-arrays connected to 70 inverters in total. To have detailed information about shadowing impact on the whole system, a 3D scene was built (Fig. 3). Surrounding trees and construction elements that can affect the PV farm were also included.

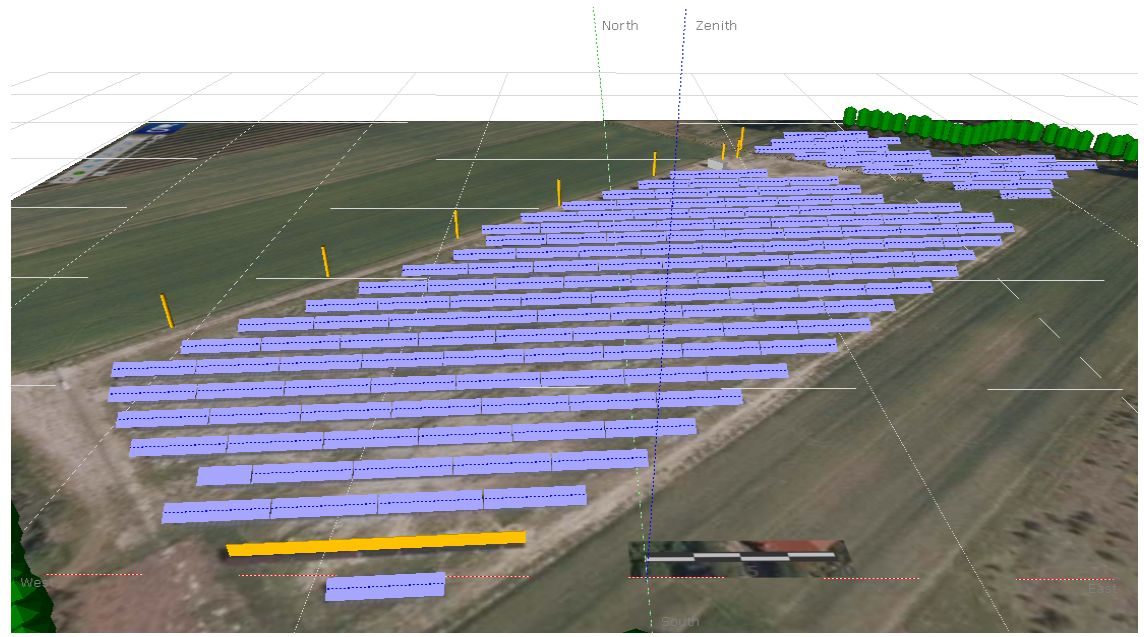

Fig. 3. Overview of the PV power plant. Scene built in PVSYST software.

It is possible to extract PVGIS meteorological data from a desired year or from a required period of time. Data containing monthly and yearly energy production of described power plant in 2015 was given in [7]. It was the reason that we decided to compare real, available data with a forecast of energy production given by simulation of the PV farm in the PVSYST software.

The simulation of the PV power plant performance was done using four different meteorological data bases described in the 2.1 section. Meteorological data extracted from the PVGIS website included:

- monthly horizontal irradiation in 2015, 
- diffused/Global radiation in 2015,

- daily average temperature in 2015 .

After performing the simulation - monthly and yearly energy production was found for each case considered.

Comparing monthly and yearly energy production helped to establish the best meteorological data given by PVGIS for eastern Poland conditions.

\section{Results and Discussion}

Comparison of the monthly energy production simulated in PVSYST with energy injected by the PV power plant into the grid in 2015 is shown in Fig. 4.

To have a better understanding about differences between each meteorological data, percentage difference between simulated energy production and energy injected into the grid was calculated and shown in the Fig. 5.

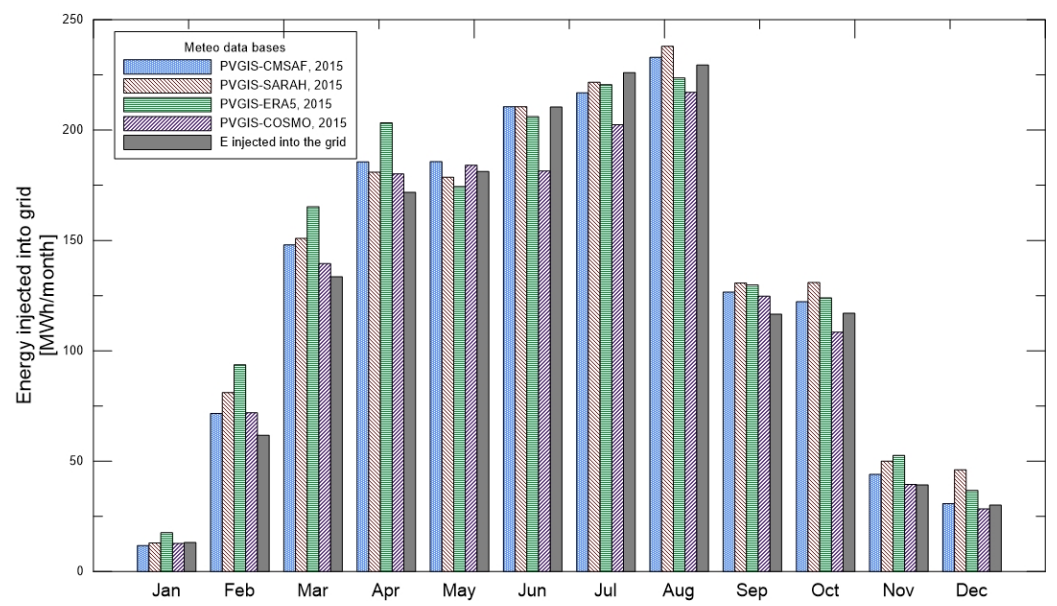

Fig. 4. Comparison of monthly energy production simulated using four different meteorological data bases with the energy injected into the grid in 2015 .

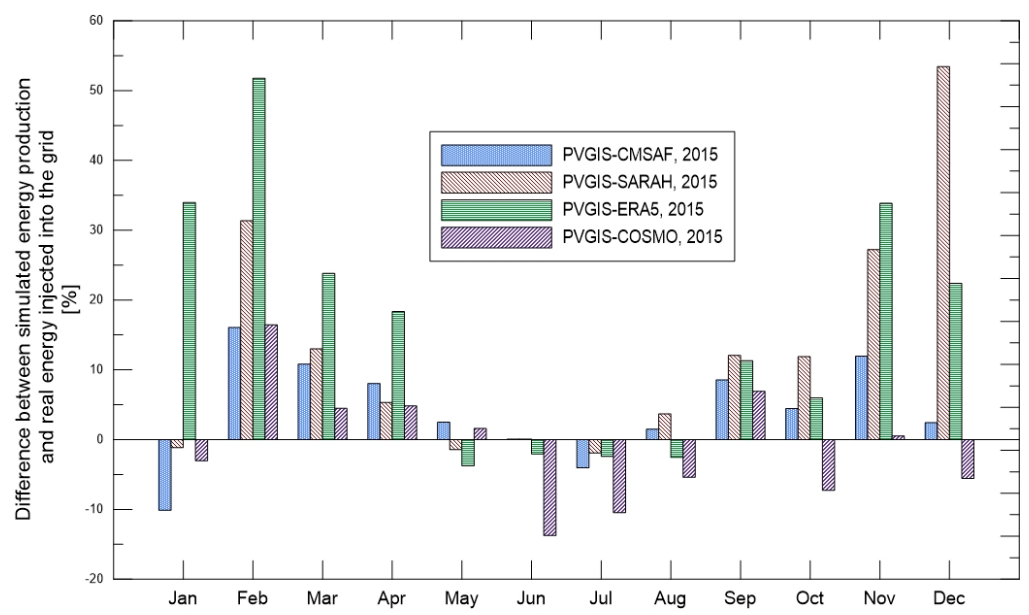

Fig. 5. Monthly percentage difference between simulated energy production and energy injected into the grid during 2015. 
As seen in the Fig. 5, the lowest differences between the energy productions based on different meteorological data are observed from May to August. Only for PVGIS-COSMO does the difference exceed $10 \%$ in favour of energy injected into the grid. Differences of the rest of the meteorological data bases range from $-4 \%$ to $4 \%$. The situation changes for autumn and winter months. The differences are higher - for example for PVGIS-ERA in March, the simulated energy production is 50\% higher than the real energy yield.

In almost all of the cases, all of the available data overestimate solar irradiation which in the end leads to higher energy production. In order to have a reliable simulation of the PV power plant, one has to introduce as many available data about the PV system as possible. Sometimes it is not possible to establish all of the significant parameters which usually lead to a decrease of the forecasted energy production. So one can expect that the simulation results will give a higher energy production than the real system. When we consider this, the PVGIS-CMSAF gives reasonably good results. During winter and spring the maximal difference reaches $15 \%$ and it slowly drops to $0.1 \%$ in June, then it slowly rises to reach values around $10 \%$. Summer 2015 was very sunny, and the Sunshine Duration exceeded the usual level by more than $220 \mathrm{~h}$ [9]. Based on this information, one can conclude that the algorithm that processes satellite data to calculate solar irradiation gives more accurate results when cloud coverage is minimal. This can be the reason that we observe the difference drop during summer months (Fig. 5)

Another parameter which was analyzed is yearly energy production in 2015 - Fig. 6a. As in the previous case, the percentage difference between simulated energy production and energy injected into the grid in 2015 was taken under consideration - Fig. 6 b.
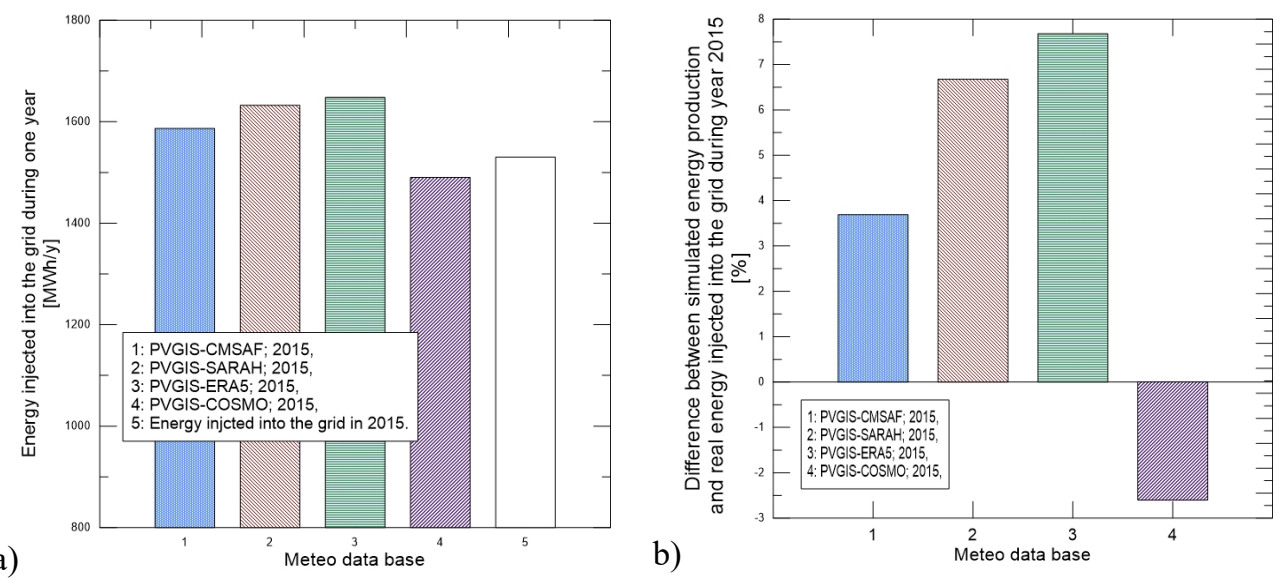

Fig. 6. Simulated energy yield in 2015 according to considered meteorological data base compared with real energy production a); percentage difference between simulated energy production and energy injected into the grid in $2015 \mathrm{~b}$ ).

The maximal difference between real energy production in 2015 and energy yield predicted by software does not exceed $8 \%$ for PVGIS-ERA (Fig. 6b), and the rest of the measurements have even lower differences from $-2.5 \%$ to $6.5 \%$.

\section{Summary}

Energy production in 2015 of the photovoltaic power plant located in Bordzilowka in eastern Poland was analyzed. It was compared to simulation results conducted in the PVSYST software for four different meteorological data bases available on the PVGIS website. Analysis of the results helped to establish the best source of the meteorological data for photovoltaic applications under conditions in eastern Poland. 
Analyzing monthly and yearly results, overestimating energy production seems to be common for each considered case. In terms of monthly energy yield, the lowest difference between energy injected into the grid and simulation corresponds to PVGIS-CMSAF data source. PVGIS-ERA5 data used for energy production prediction seems to have the worst results for the considered region - the analyzed differences are much higher compared to other data sources. In terms of energy production during one year, surprisingly the differences are not so significant. The biggest difference corresponds also to PVGIS-ERA5 but it is only a $+7.5 \%$ overestimation. The lowest absolute difference reaches $2.5 \%$ of underestimation and it corresponds to PVGIS-COSMO data, which is a slightly better result than $3.5 \%$ for PVGIS-CMSAF. But taking into account both cases - energy production during one year and prediction of the monthly yield, PVGIS-CMSAF data gives the most accurate and reliable results in terms of forecasting photovoltaic power plant performance under conditions in eastern Poland.

\section{References}

1. A. Jäger-Waldau, JRC Science or Policy Report, PV status Report 2017, (Luxembourg: Publications Office of the European Union, 2017)

2. http://re.jrc.ec.europa.eu/pvg_static/methods.html (access 12.06.2018)

3. R.W. Mueller, C. Matsoukas, A. Gratzki, H. D. Behr, R. Hollmann, Remote Sens. Environ. 113, 1012 (2009)

4. R. Müller, U. Pfeifroth, C. Träger-Chatterjee, J. Trentmann, R. Cremer, Remote Sens.. 7, 8067 (2015)

5. https://www.ecmwf.int/en/forecasts/datasets/archive-datasets/reanalysis-datasets/era5 (access 12.06.2018)

6. C. Bollmeyer, J.D. Keller, C. Ohlwein, S. Wahl, S. Crewell, P. Friederichs, A. Hense, J. Keune, S. Kneifel, I. Pscheidt, S. Redl, S. Steinke, Q. J. R. Meteorol. Soc. 141, (2015)

7. P. Dragan, A. Zdyb, J. Ecol. Eng. 18, 231 (2017)

8. PN-EN 12831:2006. Instalacje ogrzewcze w budynkach. Metoda obliczania projektowego obciążenia cieplnego

9. http://www.imgw.pl/2017/10/17/mapy-klimatu-polski/ (access 12.06.2018)

10. http://www.pvsyst.com (access 12.06.2018) 